\title{
Teaching Romanian for medical foreign students with the help of Interactive methods
}

\author{
Réka KUTASI ${ }^{1}$
}

The present study aims to highlight the importance of engaging speaking activities as a primary method for teaching Romanian as a foreign language to overseas students. The results are strengthened by a questionnaire applied to students from the Faculty of Medicine and Dental Medicine in English. As a result of the COVID-19 pandemic, face-toface classes were replaced by online ones which gave us, teachers, the possibility to use modern technology throughout our courses. The diversity of the topics included in the curriculum helped teachers to involve foreign students in different types of activities, such as speaking, interacting with their peers in order to develop elementary communication skills, but also new vocabulary learning. Even if students came from different countries and cultures, Germany, Spain, Italy, Sweden, the United Kingdom, Israel, Syria or even Ghana, they all learned Romanian to be able to interact mainly with their colleagues or people they met in their day-to-day life.

Keywords: Romanian classes, cultural differences, foreign language students

\section{Introduction}

Romania, as part of the European Union, has attracted many foreign students, in the last couple of years. Students who decide to study in a foreign country are always looking for new challenges in terms of education, travelling, personal development, etc.

The high quality of education offered by Romanian higher education institutions is appreciated all over the world. This is constantly being increased and developed by adapting the learning content to the needs of society. The National Institute of Statistics Romania performed a survey regarding the number of international students enrolled in Bachelor programs in Romania from 2014 to

\footnotetext{
1 "George Emil Palade" University of Medicine, Pharmacy, Science, and Technology of Târgu Mures, reka.kutasi@umfst.ro
} 
2020. According to the report published in July 2021 there is a 25 percent growth in the number of foreign students who started their studies in a Romanian Higher Education Institution (https://www.statista.com/statistics/1098620/internationalstudents-romania/).

The "George Emil Palade" University of Medicine, Pharmacy, Science, and Technology of Targu Mures is a multicultural university where students can study Medicine and Dentistry in three different languages: Romanian, Hungarian and English. If in the past medical education was offered only in Romanian and Hungarian languages, today, to align the university to the European standards, students have the opportunity to fulfil their studies in English as well.

Included in the curriculum, foreign language classes are compulsory for all the students who are enrolled at an educational institution. Students who study at the Romanian or Hungarian sections can choose among English, French or German classes while foreign students, who study in English, are required to learn Romanian as a foreign language (it is the official language of the country).

As a university that shapes students to become medical professionals, it is of high demand for learners to speak the language of the country. Romanian classes take place in the first two years of study while in the third year, to be able to take part in practical activities, students are required to sit and pass a Romanian exam. More, to help students master the language of the country, optional Romanian classes have been included in the curriculum for students from the third year of study.

Teaching at the George Emil Palade University of Medicine, Pharmacy, Science, and Technology of Targu Mures is a real challenge. Students from different countries choose to complete their studies at this university, either by studying Medicine or Dentistry in English. As students come from different countries foreign language teachers need to adapt their classes (e.g. materials, methodology) to obtain equal performance from each of them. Teaching is not teacher-centred, where the teacher is seen as a God/Goddess, as he/she knows everything, but student-centred, putting a high emphasis on students' needs, to develop their cognitive skills. The increase in the social, cultural and ethnic heterogeneity can also be observed in the classroom which denotes the requirement to cope with the different situations of diversity that may arise in educational organizations.

\section{Foreign students in Romania}

Being a medical student in a foreign country is a real challenge. Having arrived in a foreign place and attending classes where people speak different languages is 
something students have to get used to. There are two reasons why it is difficult to be a foreign student:

- you are taught in a language which is not your mother-tongue;

- you have to learn the language of the country to succeed in what you have proposed/planned.

Besides having to cope with learning a foreign language, students are required to learn Romanian as a foreign language, a language most of them have never come into contact with before. Hence, the need for attractive and operative teaching methods and activities is required to develop their learning/linguistic skills that will help them to easily acquire the Romanian language. The desire to learn Romanian as a foreign language becomes even greater due to students' need of being accepted and integrated in the community where they live and study (Nechifor and Borca 2020, 291).

To familiarize foreign students with the academic atmosphere (and not only) of the host university, university staff together with senior-student volunteers decided to organize the so-called Freshers' week. Thus, upon their arrival, students are introduced to the culture of our country with the possibility to learn about its places, architecture, and specific cuisine. More, they can meet and get to know each other, while being acquainted with the university and its surrounding as well as the classrooms and laboratories where the courses will be held. Unfortunately, the beginning of the 2020-2021 academic year was an unusual one, as the Freshers' week could not be organized because of the COVID-19 pandemic.

\section{Romanian classes}

We often hear teachers say "there are students from my class/group with learning difficulties" or "students do not care about the course I teach". According to Westwood (2008, 2) phrases like "learning difficulties" are used to describe students who do not achieve the expected learning outcome. The didactic process is an intricate one having interlocutors with different cultural identities and different expectations. Thus, foreign students who are accustomed to diverse educational systems and teaching styles have various learning expectations. We are often told, "In my country, these things are taught differently."

Romanian classes within the George Emil Palade University of Medicine, Pharmacy, Science, and Technology of Targu Mures are organized efficiently and practically. To achieve the best goals with their students, teachers need to take into consideration their expectations, needs and learning styles. Thus, Romanian classes 
are held within a friendly environment with small groups of students (7 to 14) where the teacher has the opportunity to motivate his/her learners and he/she has the role of a partner rather than that of a master. The syllabus is designed to reflect diversity in the classroom. From reading and speaking tasks to grammar exercises to enhance students' communication skills, Romanian lessons are interactive and student-centred. A great emphasis has been put on communication, vocabulary, cultural issues and grammar rather than on pure reading lessons. M. Byram (1997, 32) suggests that foreign language teachers should develop students' intercultural communication competence. The teacher is the 'host' while the students are the 'visitors'. They need to overcome this language barrier to acquire intercultural communication competence and be able to learn the language of their new home.

\section{Research Method}

To have a piece of clear evidence on what to emphasize when teaching Romanian to foreign students, a survey has been conducted among the students from the Faculty of Medicine and Dental Medicine in English to make correlations between the syllabus and students' needs. The survey encompassed general questions such as "How did you find out about our university?" but also questions regarding Romanian lessons and the difficulties students may experience while learning the language.

The platform that was used for the survey is Survey Planet (https://surveyplanet.com) a tool utilized by universities and corporations worldwide. The instrument allowed us to create a free survey consisting of 13 questions and offered numerous free tools to share with our students but also to analyse their responses. The survey took place in November 2020 by observing the GDPR. It helped us strengthen the hypothesis from which we started teaching the Romanian language to foreign students, more precisely that speaking tasks (dialogue, picture description etc.) are seen as interactive methods used in teaching a foreign language. There is no need for students to learn the vocabulary automatically, but by taking part in speaking tasks regularly they learn the terminology on the go. Thus, during this teaching process, the teacher is seen as a model, an organizer, an advisor but also a partner with whom students can communicate.

Eighty-eight students accepted to fill out the questionnaire, 46 males (52,3\%) and 42 female respondents (47.7\%). Out of the total number of students, 78 were from the Faculty of Medicine and 10 from the Faculty of Dental Medicine. The low number of responses from the later faculty can be explained as a result of the 
higher number of students at the Medicine study program. The effects of the COVID-19 pandemic are also reflected upon students' mood and willingness to cooperate and take part in different studies. It can also be explained as a psychological effect, thus, students need and expect motivation from their teachers when required to fulfil a certain task.

\section{Survey results}

The first two questions included in the questionnaire had the intention of finding out more about students' preferences for Romanian Higher Education Institutions and their way of searching for the best institution to study at. Being asked how they have found out about our university, the great majority of our students, more exactly, $46,6 \%$, stated that they learned about the university while navigating on the internet. $44,3 \%$ stated that their friends $(44,3 \%)$, who were already students at our university, had a significant influence on convincing them to attend the courses of our institution. More, students were motivated by the low tuition fee, but also by academic reasons.

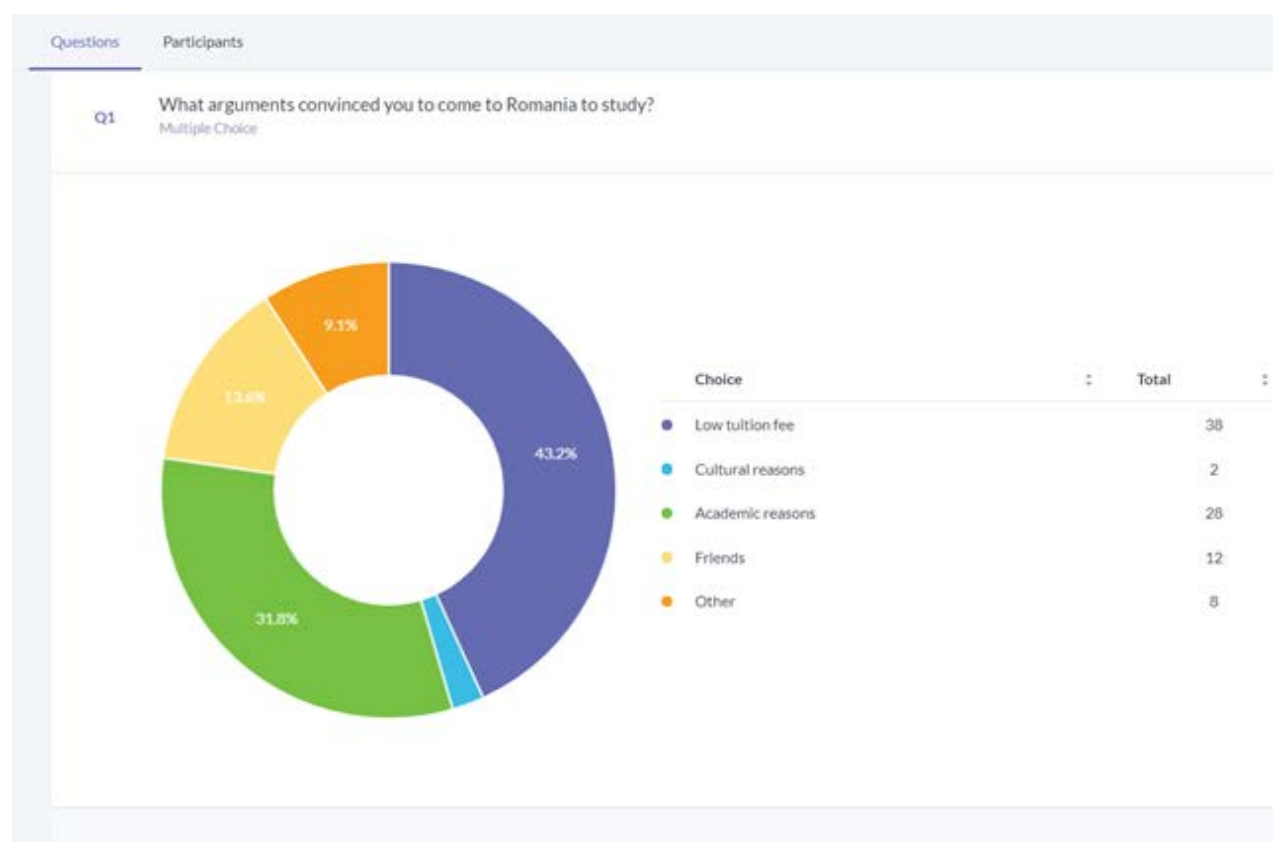

Figure 1. Question 1. What arguments convinced you to come to Romania to study? 


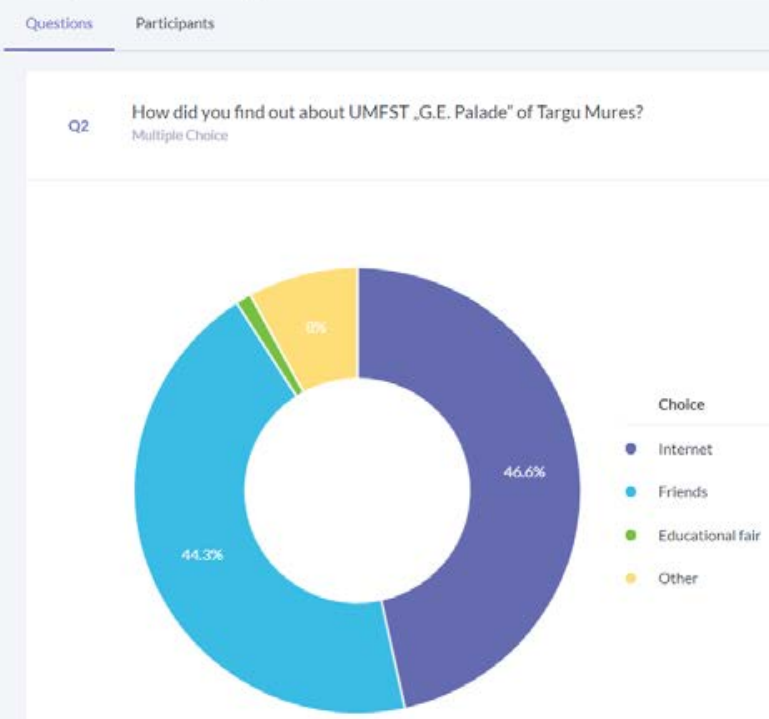

Figure 2. Question 2. How did you find out about "George Emil Palade" UMPhST from Târgu Mures?

Students were already familiar with the fact that they will have to learn Romanian as a foreign language, as starting from the third year of study, they need to interact with patients as part of their practical activities held at different hospitals from Mure; county. Being a Romance language, learning Romanian by most of our students represented a problem at first. The most difficult thing in learning the language seemed to be the grammar, according to $57 \%$ of the students, followed by the vocabulary by $18,6 \%$, while only $12,8 \%$ of students believe that pronunciation is difficult. 


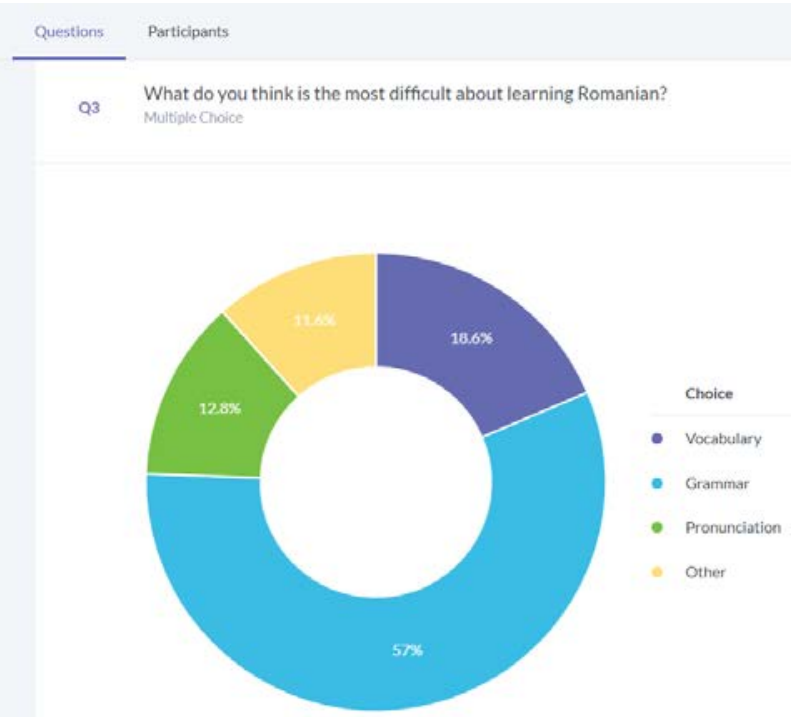

Figure 3. Question 3. What do you think is the most difficult about learning Romanian?

Most of the Romanian lessons were designed on communication activities through which students could learn vocabulary and grammar rules by doing attractive exercises and not by simply learning them by heart. Communication among students in the online environment represented the very challenge of these days, as it could hardly replace the face-to-face / on site communication. That's why, the online platform (Blackboard), with its function of "Breakout rooms" enabled teachers to replicate real-life communication (speaking activities based on images of different medical situations). These exercises help medical students to get acquainted with medical terminology, to have a conversation with their colleagues or with hospitalized patients. More, they can learn the vocabulary with the help of an attractive and easy method. The experience gained during the years made me, as a teacher, give more significant importance to communication activities which trigger, without a doubt, the possibility for students to learn vocabulary and grammar rules.

It is known that learning a foreign language takes time, a lot of effort and, more importantly, practice. The rapid development of the Internet has had a great impact on language teaching and learning ( $\mathrm{Wu}, 2012: 521)$. This change has significantly helped both teachers and students. Nowadays, the Internet is one of the most stimulating, powerful technologies that play a vital role in one's personal and professional life. It is also an unlimited source of information for language 
teaching. Foreign students have always been encouraged to use different online resources to enhance their Romanian language knowledge. Students reported using mainly online applications $(43,2 \%)$ as shown in Figure 5, Romanian books $(18,2 \%)$, but they also watched Romanian movies $(6,8 \%)$. More, $17 \%$ of the students engaged in conversations with their Romanian friends. This low percentage may result from the situation created by the COVID-19 pandemic.

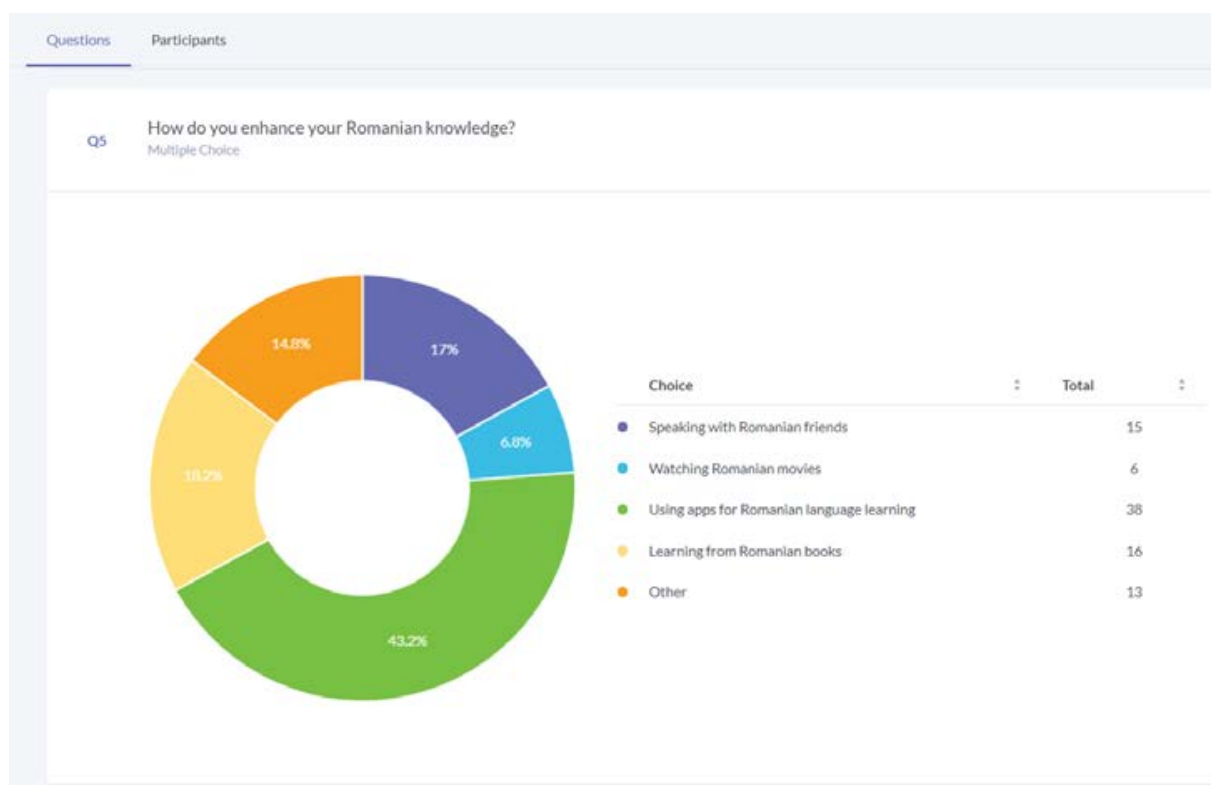

Figure 4. Question 5. How do you enhance your Romanian knowledge?

The above chart speaks for itself. More and more students started to use different apps for Romanian language learning, group work was easier to perform as Blackboard, the platform used by the university allowed the teacher to split the class into groups.

Conversation tasks were used to enhance students' pronunciation and to practice different types of dialogues. I selected some answers given by students for Question 6 from the questionnaire "What do you think is the best method to learn Romanian? Motivate your answer?" 


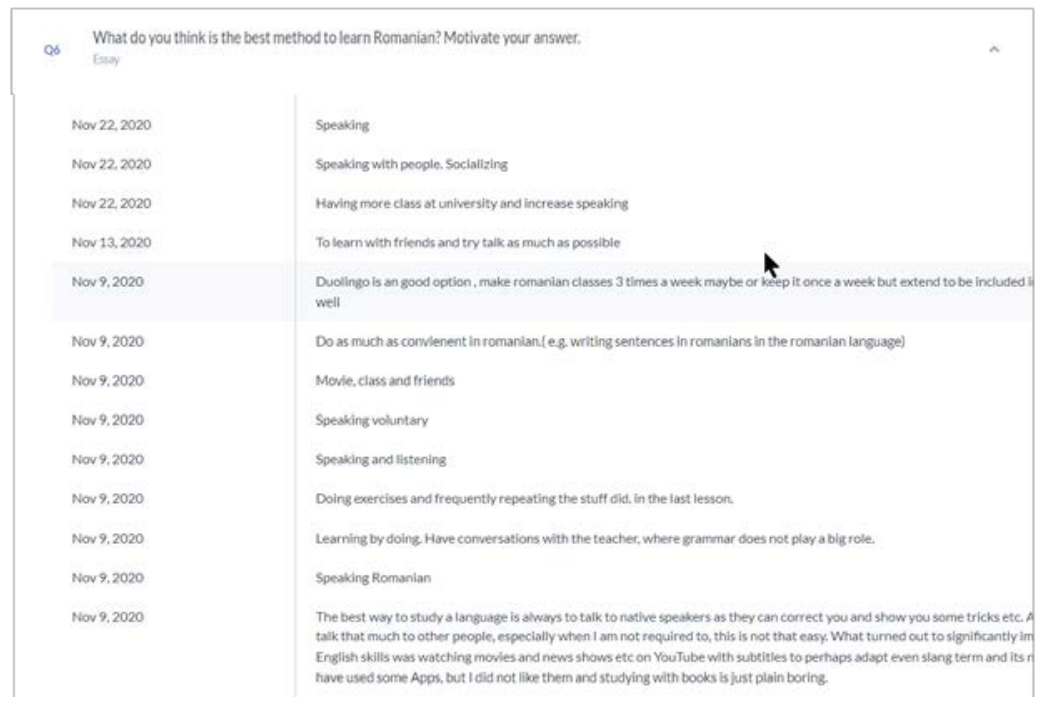

Figure 5. Question 6. What do you think is the best method to learn Romanian? Motivate your answer.

According to Penny Ur $(1996,120)$ the most essential skill with regard to daily communication is speaking. Darasawang $(2007,201)$ highlighted that a person learns a foreign language to communicate, to study abroad and/or to conduct a business. In Romania, it is essential for foreign medical students to communicate and be competent in the Romanian language in order to be able to interact with patients from hospitals or dental practices where they will perform their practical activities. Thus, speaking activities are included and considered to be the most effective and essential tasks for students to carry out throughout Romanian classes. What has been observed during the years is that students are sometimes afraid of speaking as a result of foreign language speaking anxiety which can have a negative impact on their learning process (Alnahidh and Altalhab 2020, 55). There are three major factors that can influence foreign language speaking anxiety: communication fear, fear of negative assessment and fear of failing the exam (Horwitz, Horwitz, and Cope 1986, 127). More, what the questionnaire revealed is that students are afraid of not being laughed at by their peers. In order to avoid these incidents, during speaking classes, we have motivated all our students to speak. Even if they had to describe a picture individually or in a group all the students had to speak at least once. Additionally, a great emphasis has been put on their pronunciation. 
Feedback was instantly given, students were promptly corrected thus, having the opportunity to learn from their mistakes. Error correction was made in a subtle way either by asking students if they are sure that the answer that they have given is the correct one (self-correction) or by non-verbal ways of correction (gestures, mimicry, crossed finger).

The teacher can be an influential factor in motivating students to speak. The foreign language professor should not only educate his/her students, but also create a pleasant atmosphere in the class and a good relationship with the students in order to motivate them and make them confident (Latha and Ramesh 2012, 5) Our students have come to the conclusion that practice makes them perfect as it can be observed in Figure 6.

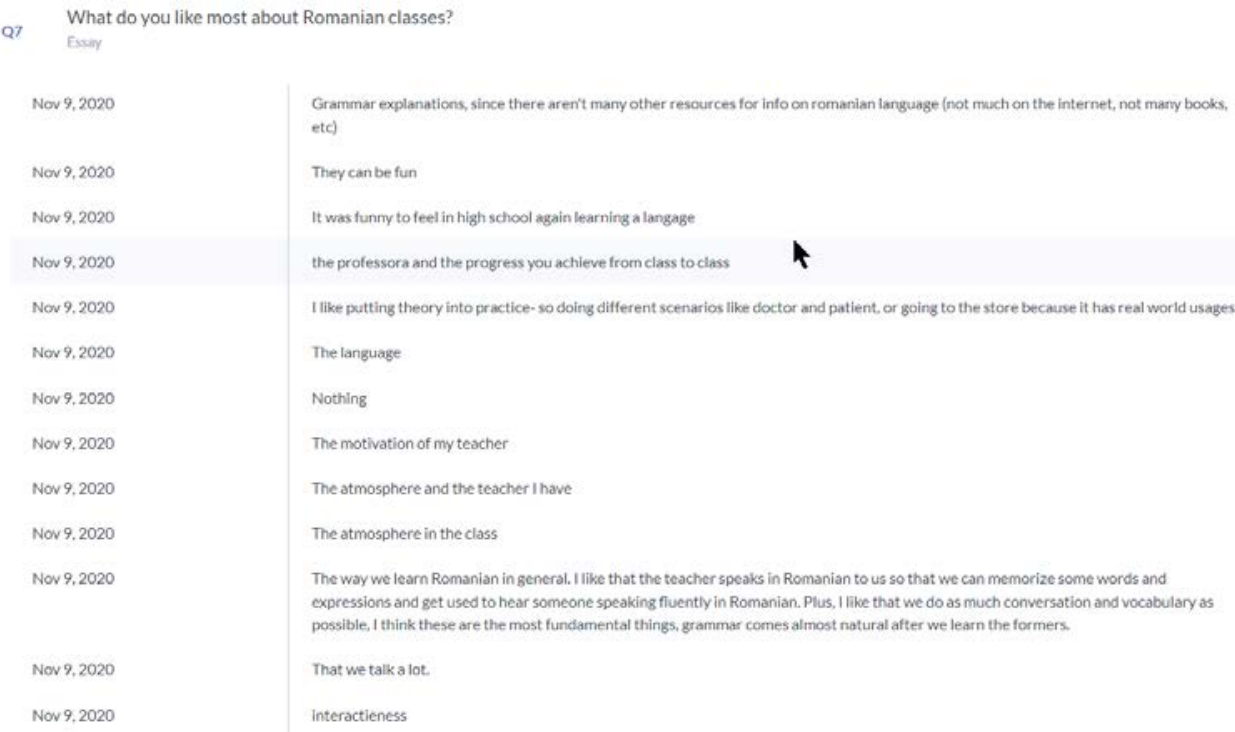

Figure 6. Question 7. What do you like most about Romanian classes? 


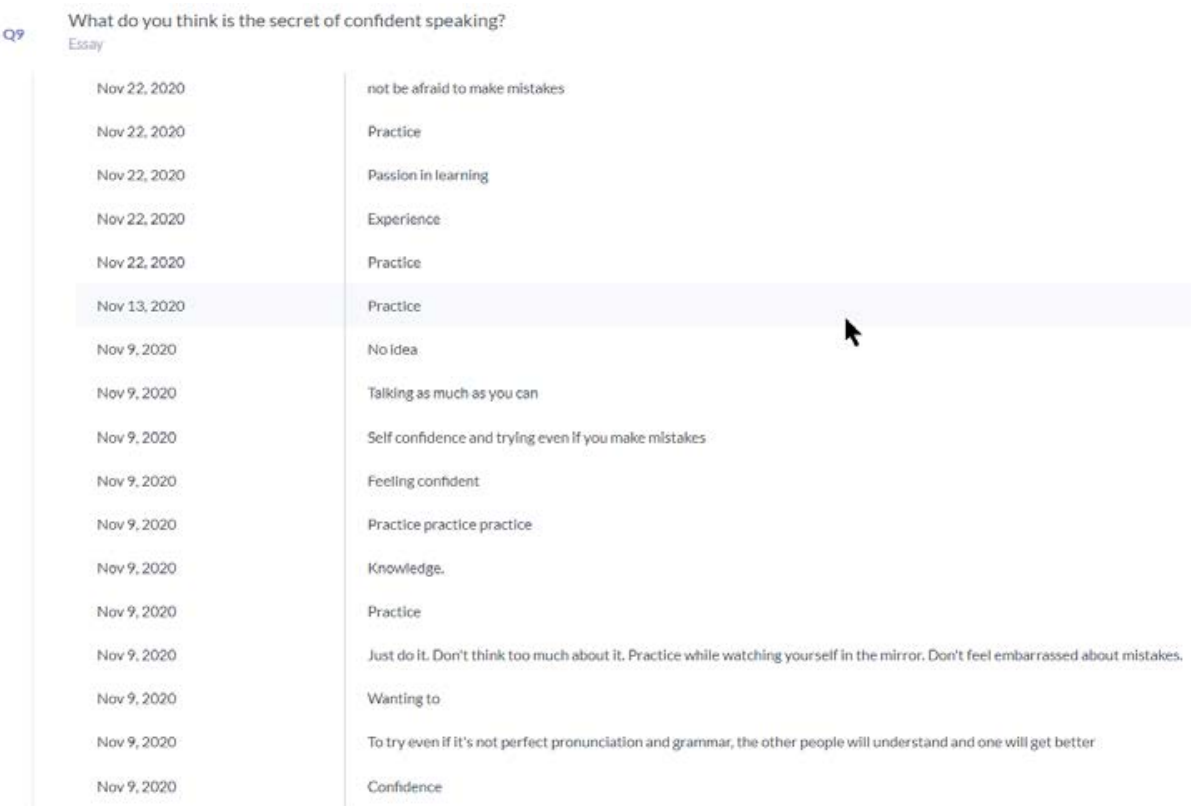

Figure 7. Question 9. What do you think is the secret of confident speaking?

\section{Conclusions}

Teaching Romanian language to foreign students of different cultures is a real challenge for teachers. In order to meet students' needs they have to adapt their teaching style, the materials and methods they use in line with their necessities. Teaching Romanian as a foreign language to students who already study in a foreign language requires a lot of effort and willingness to design attractive teaching materials that can be used to develop their communicative competence through the use of innovative teaching methods.

The study revealed foreign students' expectations and their level of satisfaction when it comes to learning Romanian as a foreign language. More, their answers can be regarded as recommendations for foreign language teachers. A teacher should create a friendly teaching environment and should encourage learners to practice speaking the language they would like to learn for their own knowledge and not for the sake of just passing a test or an exam (Alnahidh and Altalhab 2020, 58). 


\section{References}

Alnahidh, Faye and Sultan Altalhab. 2020. "The level and sources of foreign language speaking anxiety among Saudi EFL university students." Advances in Language and Literary Studies 11(1): 55-64.

Byram, Michael. 1997. Teaching and assessing Intercultural Communicative Competence. Clevedon: Multilingual Matters.

Darasawang, Pornapit. 2007. "English language teaching and education in Thailand: A decade of change." In English in Southeast Asia: Varieties, literacies and literatures, ed. by David N. Prescott, 187-204. Cambridge Scholars Publishing.

Horwitz, Elaine K., Michael B. Horwitz, and Joann Cope. 1986. "Foreign language classroom anxiety." Modern Language Journal 70: 125-132.

Latha, Madhavi B. and Pettela Ramesh. 2012. "Teaching English as a second language: Factors affecting learning Speaking Skills." International Journal of Engineering Research \& Technology 1(7): 1-6.

National Institute of Statistics Romania, Ministry of Education and Research, Number of international students enrolled in bachelor degree programs in Romania from 2014 to 2020, 22 July 2021. Accessed: 23 November 2021, https://www.statista.com/statistics/1098620/international-studentsromania/.

Nechifor, Andreea and Ana Borca. 2020. "Contextualising culture in teaching a foreign language: the cultural element among cultural awareness, cultural competency and cultural literacy." Philologica Jassyensia an XVI, nr. 2 (32): 287-304.

Ur, Penny. 1996. A Course in Language Teaching: Practice and Theory. New York, NY: Cambridge University Press.

Westwood, Peter S. 2008. What teachers need to know about learning difficulties. Carolyn Glascodine (ed.). Camberwell, Vic.: ACER Press, 2.

Wu, Dan. 2012. „Living in second life and learning a second language: A study on English learning for Chinese residents in second life." Creative Education 3(4): 520-526. 